\title{
Broadband and e-Commerce in the Balkans - Econometric Analysis
}

\author{
Chief Assist. Prof. PhD Mariana Kaneva \\ University of Economics - Varna, Varna, Bulgaria \\ kaneva_md@ue-varna.bg
}

\begin{abstract}
Broadband telecommunications are pointed out as one of the fundamental acceleration factors for economic development. Through the broadband technology, information can be sent along multiple channels, which allows more information to be transmitted at a definite moment. One of the applications of this technology is internet commerce. The scientific aim of this publication is the quantitative assessment of factor influences between broadband networks and electronic sales, and their characteristics in the Balkan states. The used methodology of the research is built upon the cointegration approach. Both long-term, static influences are assessed, and the short-term dynamics. Databases of the International telecommunication union, the World bank, Eurostat and Euromonitor are used. The research relates to the period from 2007 to 2018. The beginning of the research period is consistent with the issuance by the European commission of Recommendation C (2007) 5406, in connection with Directive 2002/21/EC. The calculations in the present publication are accomplished by means of Microsoft Excel, EViews 10. The results from the research are useful for governmental and regulatory bodies of the separate states, during the development of policies in this sphere.
\end{abstract}

Keywords: time series analysis; descriptive analysis; Cointegration Models; forecasting; broadband; Internet speed; e-commerce.

JEL Code: C22, C5, C530, L810, L86, L96; doi:10.36997/IJUSV-ESS/2019.8.2.100

\section{Introduction}

The mutual commitment, the cause and effect connection between broadband networks (the access to them, the services which they render) and the economic growth and/or economic development is a subject of many scientific studies.

In the light of the theories about endogenous growth Romer, P. M. (1990) proves, that the acceleration of economic growth is possible through facilitation and adoption of the innovative processes. The authors Madden, G., \& Savage, S. J. (1998) prove in their publications the strong economic influence of investment in telecommunication, regarding the economic development of different groups of states, including the ones from Central and Eastern Europe. During the last ten years, researchers' attention is focused on the factor influences, which broadband networks have an effect on different spheres of human activity. The construction and introduction of high-speed broadband networks is brought as a priority on a word scale and an investment in the future. In the publication Broadband infrastructure and economic growth Czernich, N. ect. (2011), the authors prove, that a growth of 10 percentage points of broadband access, increases the annual GDP growth per capita from the population with $0,9-1,5$ percentage points. There are a lot of publications, in which the dynamic interaction is studied, between broadband networks and technologies, and the economic development. The overall conclusion, which establishes itself, after a review of this part of the literature Qiang, C. Z. W., ect. (2009); Ghosh, S. (2017); Hasbi, M. (2017).; Nina Czernich, ect (2011); Biagi, F., \& Falk, M. (2017) is: there exists a strong positive relationship between the indicators of economic development and the ones which characterize networks, the investments in networks, the access to them. No less are the proofs regarding the influence of networks on separate economic sectors such as industry, construction, commerce Minges, M. (2015); Mitrović, Đ. (2015), including education and health protection. One of the most popular activities in the internet milieu is electronic commerce. Electronic commerce, as a mass phenomenon, turns into reality in 1991, when the World Wide Web (WWW) is opened to many consumers. The electronic commerce is a global phenomenon, which affects the socio-economic life of the whole world. Since the time of the 90-ies of the past century, more and more physical and legal persons trade by means of WWW. Commercial models are formed from the type B2B, B2C, etc. According to information of 
Statista.com the share of electronic commerce in the world GDP is 1,61\% (2018), while in 2013 it was $0,92 \%$.

The aim of this publication is quantitative assessment of possible relationships between broadband networks and e-trade in the states within the Balkan peninsula. The research period encompasses the last twelve years - 2007 - 2018. During that period essential, permanent changes occur in the development of telecommunication networks regarding technique and technology. Different legal documents are created and enter into force by international institutions - the World bank, OECD, the European Union, International Telecommunication Union, UNESCO. Broadband networks and their applications establish themselves as a standard for telecommunications in the 21-st century.

The development of telecommunication networks in the Balkan region is characterized by "skipping" the phase of fixed (classic) telephone networks construction with a "the last mile" connectivity. In the middle of the 90-ies of the past century, the provision with fixed subscribers' networks per 100 households varies from $3.6 \%-4.8 \%$ in the separate states (Albania), to $51 \%$ $54 \%$ (Greece), as this density is concentrated mainly in the big urban territories. The states from the region practically passed "directly" to digital telecommunication infrastructure, as in that way there was no need for them to make additional costs for synchronization between the morally old telecommunication installations and the new digital technologies. The states could construct their cellular networks within comparatively short periods of time. As of the present moment, the total density of subscribers (of fixed, cellular networks and internet) for all states in the region is over $100 \%$. With the development of networks and their applications, the development of electronic commerce became possible for the population and business of the Balkan states. A useful research of electronic commerce about the states from the region, of Madalina-Vanesa Vargas (2018) substantiates the conclusion, that ,an increase of the networks consumers number is expected, as well as the number of users, who use the networks for electronic sales in each country. MadalinaVanesa Vargas proves, that "population and GDP in the separate state are essential factors for the volume of electronic commerce of each of them".

\section{Data and methodology}

The possibilities of electronic commerce, regarding the deepening of specialization in one or another field, the building of efficient logistic channels and supply chains, the decrease of transaction costs, the increase of competitiveness, the decrease of delivery times, etc. have been proven. In the publication, we shall adhere to the definition, deducted from UNCTAD (2015) "Electronic commerce is defined as "production, distribution, marketing, sale or delivery of goods and services from a distance, through the use of telecommunication networks, predominantly through internet.". Electronic commerce is a new way of connecting producers, traders and consumers from all over the world. In a survey of the International Trade Centre it is pointed out, that ,the sales of electronic commerce on a world scale have grown with $13 \%$ in 2017 (related to the preceding year), as they have reached approximately 29 trillion USD. Also there, it has been pointed out, that "business to business" (B2B) electronic trade continues to dominate and constitutes $88 \%$ from all online sales. In business to consumer (B2C) electronic sales, the biggest growth is reported - 22\%, and they reach 3.9 trillion USD in 2017. For the Balkan states, a twodigit growth is forecasted (by different analyzers) for B2B, as well as for B2C. Research in this field is impeded from the viewpoint of informational security. As Vargas (2018) mentions, „one fundamental problem, which accompanies each and every research, which is grounded on statistic tools - the statistical data about electronic commerce, telecommunication infrastructure of the Balkan states are not very popular, some of them are confidential, and precise, correct data are hardly found, about every state". In the concrete research, the informational security is through different databases, including the ones from ITU, the World Bank, the OECD, Our World in Data.

The results from the research prove interrelations between the growth rates of e-trade retail 
sales and the growth rates of broadband connectivity. The indicators, which characterize the broadband connectivity in the separate states are Fixed Broadband Internet subscribers (thou), Mobile broadband subscriptions (thou), Internet speed (Mbps), International Internet bandwidth (Mbps). Broadband is a generally accepted term for a high-speed connection with Internet. According to one of the ITU definitions, (2011) Broadband access is the one, which provides an information exchange speed over $256 \mathrm{~Kb} / \mathrm{s}$, independently of the fact, that this speed varies at different moments and for separate parts of the network. With the evolution of telecommunication networks and systems and technologies, the broadband definition is developed as well. In the revised methodologies for measuring of the information society ITU (2019) defines as "broadband" the access which secures simultaneously the transfer of voice, data and video services, at an "online" connectivity with a recommended lower limit of $2 \mathrm{Mb} / \mathrm{s}$. In the research, the total number of fixed and the total number of mobile broadband subscribers are used.

In order to provide comparability from the viewpoint of the scope of aggregates in the separate countries, the internet trade retailing data in the separate states are used in the research. Internet Retailing is sales of consumer goods to the population and business via the Internet. Internet retailing includes sales generated through e-commerce web sites and through sites operated by store-based retailers. The preference for this indicator is based on the fact, that exactly through it, the distribution of this kind of commerce within the population could be thoroughly assessed, and not based on excerpts. In the EU member states for the assessment of the spreading of electronic commerce, the speed of its change, etc, data from sample surveys are used, which cannot guarantee a comparability of scope. Regarding all other indicators, which characterize the electronic commerce volumes from the B2B type, we could not find, comparable data within the studied period (2007 - 2018), as well as on scope - a thorough observation.

The research instruments in the study are based on the methods of time series analysis. The possibilities of the cointegration approach are used. This approach in the time series analysis gains on popularity and establishes itself, as one of the methods through which "false" relationships between two or more macroeconomic indicators are overcome. Based on the cointegration approach are the useful works of Newbold, P., \& Granger, C. W. J. (1974); Granger, Clive WJ.(1981); Robert F. Engle; C. W. J. Granger (1987); Granger, C. W., Newbold, P., \& Econom, J. (2001) and ect. The philosophy of the method, its theoretical prerequisites and their possibilities for practical aims, are well documented in the specialized literature, aimed at the analysis of time series.

The preferences of the cointegration approach are based on the fact, that the development of networks and the sales volume in a definite time period is predetermined not only but the current indicators values, but from the preceding ones as well. In this study, this "belated" influence is supposed to be even more expressed. On one hand, users of broadband services get used to the procedures of using subscriber end devices and their abilities within a definite time span. On the other hand - time is necessary for the construction and introduction and spreading of broadband networks. Econometric models built on the cointegration approach are possess considerable advantages: they do not impose a preliminary differentiation of the variables, participating in the system of endogenous and exogenous; at a proven availability of a cointegration relationships between the participating variables, the models provide an opportunity for assessment of long-term and short-term interdependence within the framework of one single model. For a practical use, in real economic studies, a substantial inconvenience was established, characteristic for a type of models - an extensively big number of coefficients. The latter imposes the necessity of a big enough number of observations, with the aim of securing the theoretical prerequisites, regarding the examinations of the significance of the coefficients, regarding the stability of the systems as a whole and of each equation in them. In this regard, the indicator "internet retailing" has been transformed from annual and quarterly data, as the "Low to high frequency method" has been used, included in EViews 10. After the conversion, we managed to secure the minimum necessary (from a theoretical point of view) number of observations about the main indicators participating in the system - sales 
volume, Internet speed (Mbps), and International Internet bandwidth (Mbps). The volume of electronic sales is converted into comparable prices in 2017. For the purpose of econometric modeling all the variables involved are logarithmically transformed. The log transformation, a widely used method to address skewed data, is one of the most popular transformations used in time series analysis. Logarithmic transformation ensures compatibility of the indicators under consideration, as well as providing averages located within a range. In addition, (Lütkepohl, H., (2012) it is proved that, because changes in the natural logarithm are (almost) equal to percentage changes in the original series, it follows that the slope of a trend line fitted to logged data is equal to the average percentage growth in the original series.

Through the prism of the cointegration approach, we review the electronic commerce, measured by the volume of electronic retail sales in the separate Balkan states as a function from the telecommunication networks development, more specific broadband networks:

$$
I R_{t}=f\left(\mathrm{Net}_{t}, \varepsilon_{t}\right)
$$

where:

- $I R$ - Internet retailing in the Balkan states at a moment $\mathrm{t}$,

- Net - indicator(s), which characterize the development of broadband networks at a moment t. - Internet speed (Mbps), International Internet bandwidth (Mbps).

$-\varepsilon-$ is a random error term (random component) related to the operation of other possible independent (input) variables which are not included in this model.

Telecommunication networks are the environment, in which electronic commerce develops. Without this transferring environment, we would not be able to talk about electronic orders, payments and other conveniences, which contemporary networks create. There are enough reasons to think, that between electronic sales and broadband networks there exists a permanent, stable relationship, i.e. "a stable equilibrium state". An equilibrium state is defined by economic theory as the one, in which economic powers are "equal" and at the lack of external shock influences remain unchanged. In the sense of econometrics - there is a durable, linear combination between the trends of indicators, characterizing economic commerce (as a whole and by separate kinds), and the ones of broadband networks. With the development of technology and the opportunities which electronic commerce offers, there are enough reasons to think, that the equilibrium between them could be disrupted at one point or another (e.g. a breakdown in the systems due to a disrupted electric power and/or the occurrences of a natural cataclysm which to disrupt the integrity of the network, etc.). At an equilibrium state, a short-lasting state of imbalance can and does regenerate in a long-term aspect. Through the cointegration approach we assess the long-term interrelations between indicators for telecommunication networks and the volumes of electronic commerce.

The general appearance of the cointegration system is:

$$
\text { (1) } \Delta_{Y_{t}}=Y_{t-1} \Pi+\sum_{j=1}^{p-1} \Delta_{Y_{t-j}} \Gamma_{j}+\Phi \cdot D_{t}+v_{t}
$$

Where: $Y_{t^{-}}$a vector from $k$ explore variables, specific indicators volume of electronic retail sales, Fixed broadband Internet subscribers (thou), Mobile broadband subscriptions (thou), Internet speed (Mbps), International Internet bandwidth (Mbps) etc. $\Gamma_{j}$ - coefficients matrix, through which the short-term dynamics between the participating variables is assessed. The columns of the matrix $\Pi$ have been deducted as Engle, R., \& Granger, C. (1987) cointegration vectors, as each vector could be expanded in a cointegration subspace $\beta$. The coefficients from such an expansion form a matrix $\alpha$ with dimensions $(k \cdot r)$, so that $\Pi=\beta \cdot \alpha^{\prime}$. (The rank of the matrix $\Pi$ cannot exceed $r$ ). The matrix $\alpha$ contains the feedback coefficients. They characterize the speed of system adaptation to a long-term equilibrium at a deviation of the equilibrium trajectory. Matrix $\beta$ contains the cointegration vectors, through which the long-term connection is assessed between the variables in 
the system. $D_{t}$ - deterministic vector (a constant, a trend, seasonal fictive variables, etc., and $\Phi$ matrix of the coefficients for $D_{t}$. Johansen's test has been used (1988) about the availability of a long-term interrelation between the variables. Practically, this test uses methods, defined by Dickey D., Fuller, W. A. (1979), as it develops it further for the cases of vector autoregression. Apart from that, Johansen's method allows the cointegration rank to be determined (the quantity of cointegration vectors), and the type of the cointegration vectors, through a series of examination of statistic hypotheses. Johansen's test is multidimensional and allows the interdependencies between the studied variables to be examined, within the frameworks of a system of equations. The examination regarding the order of integration of the dynamic sequences, has been performed in compliance with the requirements of the unit root tests Dickey D., Fuller, W. A. (1979) and stationarity (Kwiatkowski, D., Phillips, P. C., Schmidt, P., \& Shin, Y. (1992)

\section{Results and discussion}

The descriptive analysis of all indicators, included in the study, demonstrates the availability of a strongly expressed trend. After the examinations (which are necessary in connection with the application of cointegration analysis), it is established, that the sequences composed from the volumes of electronic retail payments and the ones, which characterize the development of broadband networks, are characterized by a strongly expressed increasing development tendency. A reason for that (according to us) is the fast construction and development of all communication networks of these states and the "leap" with which they passed from fixed to cellular networks, as well as from analog to digital ones. Some of them are "young" states, which had to build their infrastructure intensively. It is impossible assessments to be made, related to volumes of internet sales, without taking into account the number of internet subscribers. In all states, the number of subscribers, and the number of internet users are realized from sample data. The results, which are reported for the separate states demonstrate, that the speed with which these indicators grow for the period 2007 - 2018 is very high. Internet subscribers in Bosnia and Herzegovina have increased 40 times, in Serbia the increase is - 29 times, Macedonia - 24 times. Internet users in all states increase between twice (Bulgaria) and fivefold (Albania). Broadband subscribers (totally) do also increase substantially. One of the indicators, which is observed by various international institutions, including ITU, the World Bank and the European Commission, is the provision of the population with a broadband access. It can be seen (Fig.1.), that the number of users per 100 persons/population in each of the Balkan states is substantially increased in 2018, compared with the one from 2007. The average annual increase rates are within borders of $6 \%$ (Slovenia) to $44 \%$ (Albania). The average annual subscriber increase in Bulgaria is $15 \%$. The number of individual uses of the Internet is increasing in each country. (Fig.2).

Independently from the high values of the reviewed indicators (internet users, internet subscribers, broadband networks subscribers), the percentage of persons who have "basic digital skills" is still low ${ }^{1}$. Concretely for Bulgaria, for the persons who possess digital skills, this percentage is $18 \%$, whereas in Slovenia it is $34 \%$, in Serbia, Montenegro - $35 \%^{2}$ Figure 3.

With the presumption, that $I R_{t}=f\left(\mathrm{Net}_{t}, \varepsilon_{t}\right)$, the sales volume is a result of the network development, as well as the network is an environment for the development of sales, we expect high values of the coefficients, which characterize this interdependence in a long-term as well as shortterm aspect. Against the background of the comparatively low digital skills, broadband networks in all Balkan states are characterized by a high internet speed, with a broad international band for traffic transference. Bulgaria is in the first 20 states regarding data transmission through the

\footnotetext{
${ }^{1}$ The basic digital skills are assessed by chosen activities, performed by persons 16-74 years old in internet in the four specific fields: (information, communication, problem solving, content creation). It is accepted, that people, performing definite activities, possess the corresponding skills; consequently the indicator could be viewed as a substitute of people's digital competences and skills.

${ }^{2} \mathrm{https} / / /$ ec.europa.eu/eurostat/data/database
} 
network, as well as the width of the bandwidth. It is necessary to make a difference between Bandwidth and Speed. Bandwidth is the capacity and speed is the transfer rate. The broader $\mathrm{f}$ bandwidth band does not mean a higher speed of data transmission. The broader band is the secured capacity, along which the data could pass. The speed with which the data through the capacity are transferred depends on the various technical devices and software applications. This speed is determined by the capacity of the internet provider as well, the "last mile", as well as the separate end users' devices.

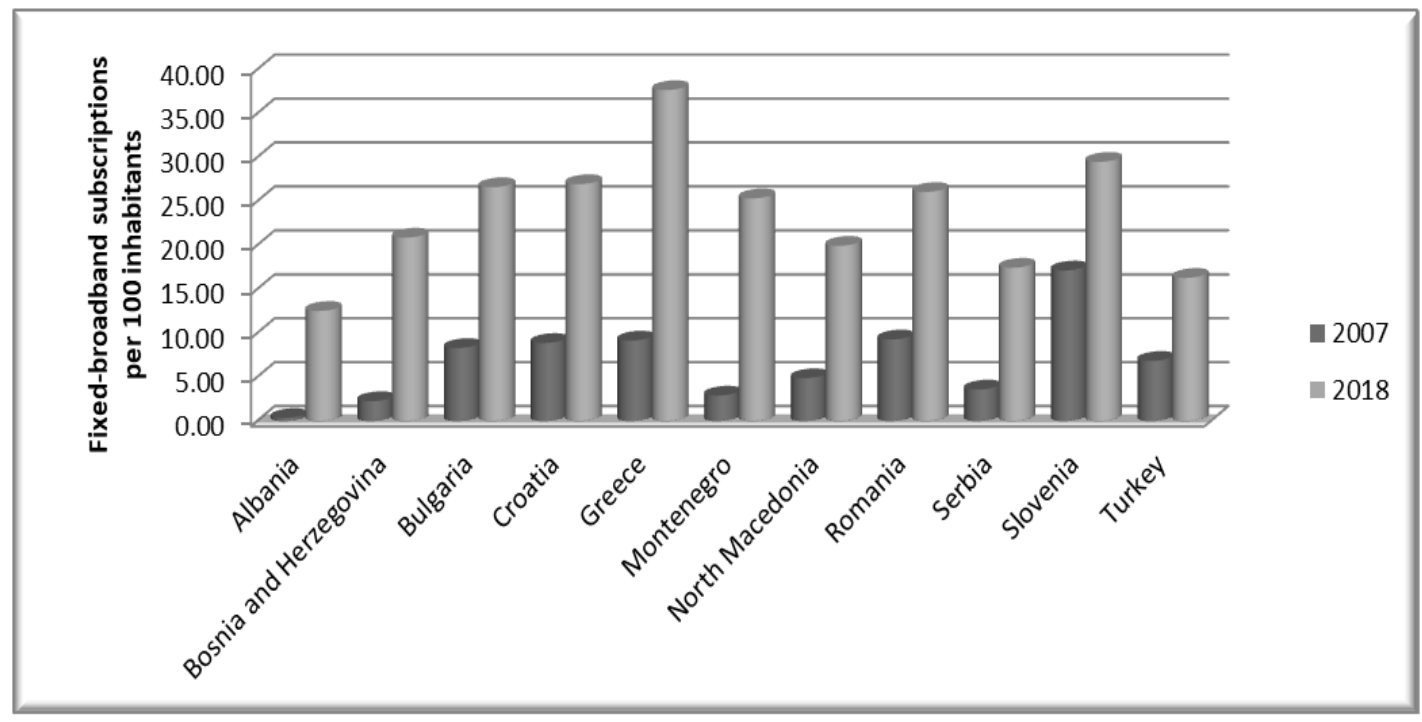

Figure 1. Fixed-broadband subscriptions per 100 inhabitants, Source: ITU

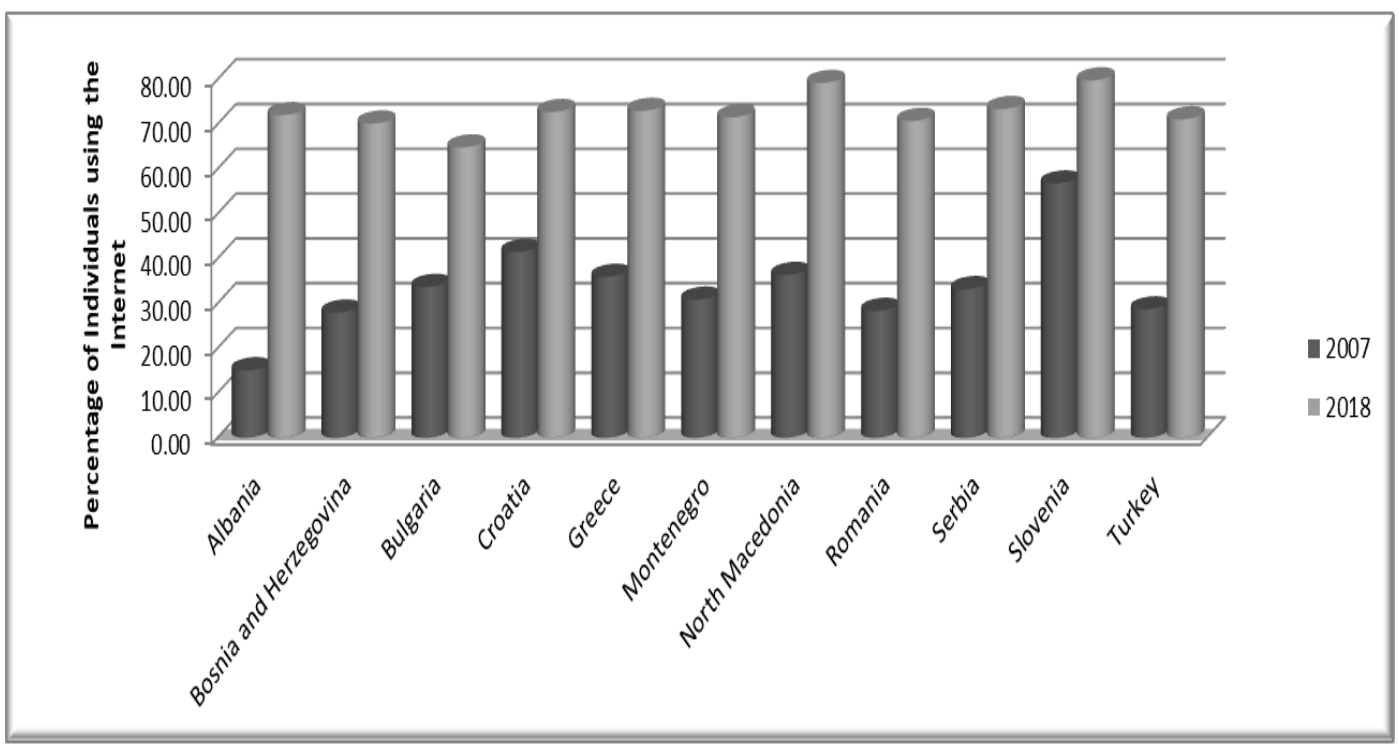

Figure 2. Percentage of individuals using the Internet, Source: Eurostat

As a result, from the application of the cointegration approach (Table 1), it is established, that between the indicators of Macedonia and Bulgaria a system is reached, in which the network speed, the width of the band and the sales volume are included. The results ${ }^{2}$, from the assessment of the system for Macedonia show, that for the growth of retail electronic sales the width of the bandwidth band, as well as the network speed are from substantial importance. In a long term perspective, at an annual growth of the data transfer speed of $1 \%$, at sales are expected to increase 
with $1,21 \%$. The influence, which the contracted network capacity exercises is lower - at a growth rate of $1 \%$ of the band width, the volume of internet sales is expected to increase by $1,03 \%$. The assessments of the short-term dynamics coefficients show, that the inertia gathered by the consumers in Macedonia, at the generation of retail sales, as well as the width of the band are from significance for the increase of internet retail trade. The results for Bulgaria demonstrate that the volume of electronic retail sales is strongly elastic, in regard to the width of the international bandwidth, as well as related to the transmission speed within the network. At a growth of the band width with $1 \%$ (or 10,24 Mbps), the sales volume is expected to increase by $5,79 \%$ in the long run. As far as the transmission speed is concerned, - the expected growth is $1,21 \%$ for the same change. With regard to the short-term dynamics - it is clearly seen in model 2 , that the collected inertia at electronic sales increases its influence in the course of time.

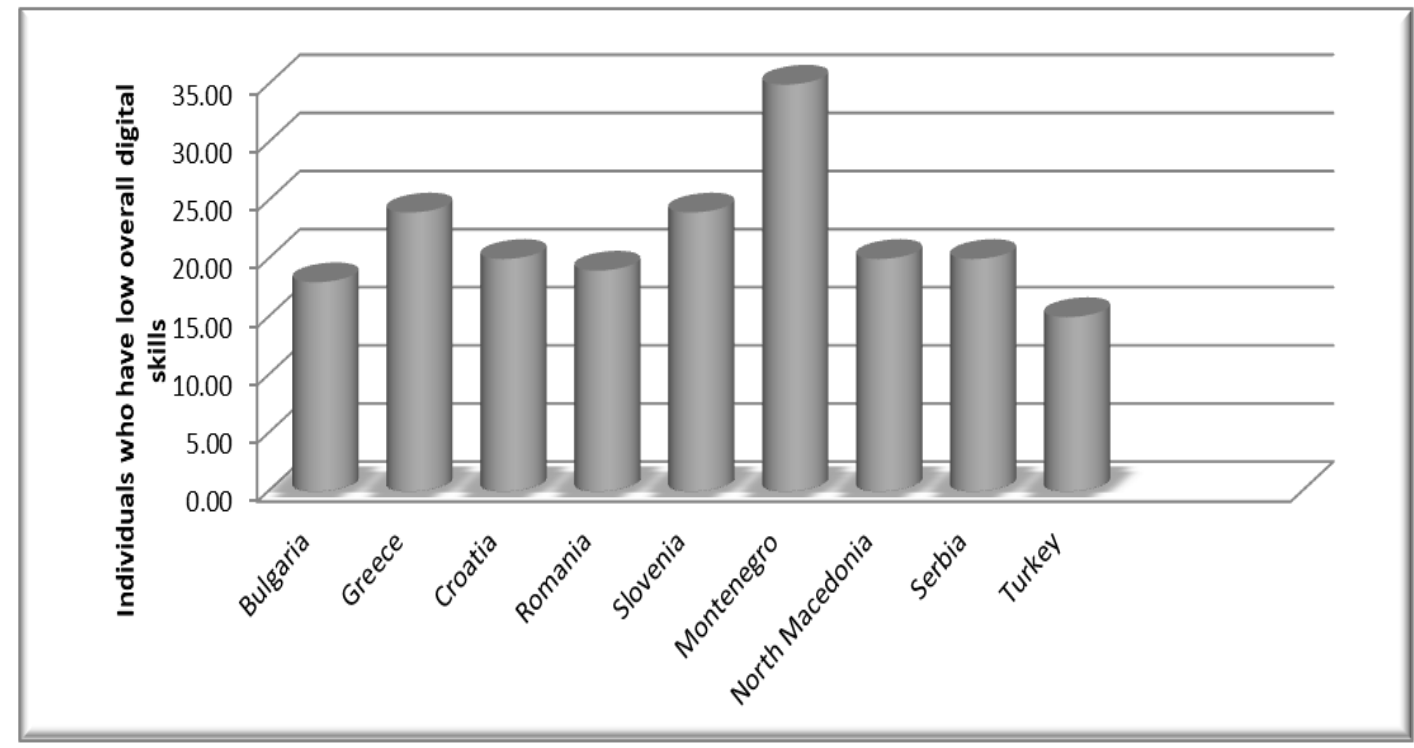

Figure 3. Individuals who have low overall digital skills, Source: Eurostat

As a result from the computations (Table 1), it can be asserted, that the data transmission speed in the network has a stronger influence on the volume of internet retail sales in the Balkan states, than the contracted international capacity for data transfer. The increase of the sales volume is nearly with $2 \%$ (in Romania) at an average speed increase of $1 \%$, in Bosnia this increase is $1,45 \%$. Regarding these states' capacity - the increased capacity of $1 \%$ stimulates just $0,15 \%$ (in Bosnia) and 0,31\% (in Romania) growth in electronic retail sales.

In Slovenia, Croatia and Turkey, the volume of electronic retail sales is not substantially influenced by the speed of the internet network and by the width of the bandwidth. This result is hard to explain, as the network itself and its capacity are supposed to be the main environment for the proliferation of electronic trade. The digitally competent people in Slovenia have the greatest share among other groups of people categorized by digital competence. Apart from that, Slovenia is at high positions in the charts for overcoming digital division, according to the network readiness index. Our assumption regarding the results, accomplished in Slovenia is, that the sales volume there is stimulated mostly by the short-term dynamics and the inertia, which the consumers have accumulated.

The results from the computations are indicative of the fact, that the end consumer, the one that generates electronic retail sales is not especially interested in the contracted international capacity of the internet network. The network speed is an important factor for its "participation" in electronic commerce. We expected much higher values of coefficients of the long-term influence of the network capacity, as well as regarding the data transfer speed. The only explanation of such a 
result (according to us) is the low level of "digital literacy" among the population in the Balkans. (Table 1). Independent of the aim of this publication, though in connection with the discussed problems, it is necessary, that we make one more specification. We have established, in our preceding research, that the income levels (measured by GDP per capita) influences directly the volume of internet sales. It is established, that in states with lower income levels the speed of changes in the sales is faster, related to the one in states with higher incomes.

Table 1. Relationships between Internet retailing and Broadband network

\begin{tabular}{|c|c|}
\hline Countries & Long-term and short-term relationships \\
\hline \multicolumn{2}{|r|}{ Internet retailing, International bandwidth \& Internet speed } \\
\hline $\begin{array}{l}\text { Model 1: } \\
\text { North } \\
\text { Macedonia }\end{array}$ & $\begin{aligned} \Delta_{(I R)}=-0,208 . & {\left[I_{t-1}-1,03 \cdot \text { Band }_{t-1}-1,21 . \text { Speed }_{t-1}-6,93\right]+} \\
& +0,28 I R_{t-1}+0,38 . \text { Band }_{t-1}+0,87 \text { Speed }_{t-1}+0,085 .\end{aligned}$ \\
\hline $\begin{array}{l}\text { Модел } 2 \\
\text { Bulgaria }\end{array}$ & $\begin{array}{l}\Delta_{(I R)}=-0,34 .\left[I_{t-1}-5,79 . \text { Bandw }_{t-1}-1,21 . \text { Speed }_{t-1}-0,25 . T r+6,2\right] \\
+0,38 . I R_{t-1}+0,78 . R_{t-2}-0,02 . \text { Speed }_{t-1}+0,65 . \text { Speed }_{t-1}+0,051\end{array}$ \\
\hline \multicolumn{2}{|r|}{ Internet retailing \& Internet speed } \\
\hline $\begin{array}{l}\text { Model } 3 \\
\text { Bosnia and } \\
\text { Herzegovina }\end{array}$ & $\begin{array}{l}\Delta_{(I R)}=-0,84 .\left[I_{t-1}-1,45 . \text { Speed }_{t-1}+1,72\right]- \\
-0,09 . I R_{t-1}+0,13 . I R_{t-2}+0,34 . \text { Speed }_{t-1}+1,17 . \text { Speed }_{t-1}+0,16\end{array}$ \\
\hline $\begin{array}{l}\text { Модел } 4 \\
\text { Turkey }\end{array}$ & $\begin{array}{l}\Delta_{(I R)}=-0,15 .\left[I R_{t-1}-0,85 . \text { Speed }_{t-1}+5,89\right]+ \\
+0,41 \cdot I R_{t-1}+0,063 \cdot I R_{t-2}+0,08 . \text { Speed }_{t-1}+0,11 . \text { Speed }_{t-1}+0,10\end{array}$ \\
\hline $\begin{array}{l}\text { Model } 5 \\
\text { Croatiag }\end{array}$ & $\begin{array}{l}\Delta_{(I R)}=-0,14 .\left[I_{t-1}-0,68 . \text { Speed }_{t-1}+3,40\right]- \\
-0,40 . I_{t-1}-0,26 . I R_{t-2}+0,07 . \text { Speed }_{t-1}+0,06 . \text { Speed }_{t-1}+0,04\end{array}$ \\
\hline $\begin{array}{l}\text { Model 6) } \\
\text { Romania }\end{array}$ & $\begin{array}{l}\Delta_{(I R)}=-0,11 \cdot\left[I_{t-1}-1,96 . \text { Speed }_{t-1}+1,205\right]+ \\
\quad+0,63 \cdot I R_{t-1}+0,17 \cdot I R_{t-2}-0,05 . \text { Speed }_{t-1}+0,17 . \text { Speed }_{t-1}+0,07\end{array}$ \\
\hline $\begin{array}{l}\text { Model } 7 \\
\text { Slovenia }\end{array}$ & $\begin{array}{l}\Delta_{(I R)}=-0,15 .\left[I R_{t-1}-0,58 . \text { Speed }_{t-1}+3,71\right]+ \\
+1,32 . I R_{t-1}+1,21 . I R_{t-2}+0,21 . \text { Speed }_{t-1}+0,07 . \text { Speed }_{t-1}+0,05\end{array}$ \\
\hline \multicolumn{2}{|r|}{ Internet retailing \& International bandwidth } \\
\hline $\begin{array}{l}\text { Model } 8 \\
\text { Bosnia and } \\
\text { Herzegovina }\end{array}$ & $\begin{array}{l}\Delta_{(I R)}=-0,69 \cdot\left[I R_{t-1}-0,15 . \text { Band }_{t-1}+0,55\right]+ \\
+0,28 \cdot I R_{t-1}+0,24 . I R_{t-2}-0,45 . \text { Band }_{t-1}+0,81 . \text { Band }_{t-2}+0,015\end{array}$ \\
\hline $\begin{array}{l}\text { Model } 9 \\
\text { Turkey }\end{array}$ & $\begin{array}{l}\Delta_{(I R)}=-0,39 .\left[I R_{t-1}-0,51 \cdot \text { Band }_{t-1}+1,27\right]+ \\
+0,22 \cdot I R_{t-1}+0,11 \cdot I R_{t-2}+0,16 . \text { Band }_{t-1}+0,57 . \text { Band }_{t-2}+0,09\end{array}$ \\
\hline $\begin{array}{l}\text { Model } 10 \\
\text { Croatia }\end{array}$ & $\begin{array}{l}\Delta_{(I R)}=-0,107 \cdot\left[I R_{t-1}-0,49 \cdot \text { Band }_{t-1}-0,01\right]- \\
-0,47 \cdot I R_{t-1}-0,29 \cdot I R_{t-2}+0,02 . \text { Band }_{t-1}+0,01 \cdot \text { Band }_{t-2}+0,05\end{array}$ \\
\hline $\begin{array}{l}\text { Model } 11 \\
\text { Romania }\end{array}$ & $\begin{array}{l}\Delta_{(I R)}=-0,245 .\left[I R_{t-1}-0,31 \cdot \text { Band }_{t-1}-8,13\right]- \\
+0,28 \cdot I R_{t-1}+0,16 \cdot I R_{t-2}+0,22 \cdot \text { Band }_{t-1}+0,13 \cdot \text { Band }_{t-2}+0,34\end{array}$ \\
\hline
\end{tabular}

The electronic sales volume on its part has an influence on the speed of GDP changes as well. This two-way causality is not a surprise - the sales, through BDS directly affect the GDP. Results from a study for Bulgaria can be found in Dimitrova, V., M. Kaneva (2018). The policies in the Balkan states have to be directed to the creation of conditions for the young and elderly ages in digital skills. It would be good if this training is realized not only at schools and universities, but in different forms of professional qualification. A good practice was the establishing of Professional Training Centers and the assisting of their activity, regarding courses which are directly aimed to 
the creation of skills and the improvement of such, connected with digital skills, not only at a basic level. Documents in this direction have been created by different national and international institutes. Each one from the Balkan states comes up with different strategies, published in a number of documents regarding the priority development of broadband networks.

\section{Conclusion}

The results from the research confirm the strong role and significance of technologies in the field of electronic commerce, including the retail one, and the broadband networks in the Balkan states. It is established, that in all states in the study, the levels of the contracted international capacity for information transfer increase after 2015. The low levels of digital competence, together with the "brief" stay in educational rooms cannot compensate the developed broadband infrastructure at the Balkans. In the course of this study it is established, that the end users, who generated internet retail sales are "interested" more in the speed with which they surf in internet, and not in the capacity, which such surfing can provide. In relation to the short-term dynamics - in the greater part the sales in the separate states are more influenced by the inertia of shopping through the network, than in the network itself and its speed.

\section{References}

1. Romer, P. M. (1990). Endogenous technological change. Journal of political Economy, 98 (5, Part 2), S71-S102. Available from: http://pages.stern.nyu.edu/ promer/Endogenous.pdf

2. Madden, G., \& Savage, S. J. (1998). CEE Telecommunications Investment and Economic Growth. Information Economics and Policy, 10(2), pp. 173-195 Available from https://mpra.ub.uni-muenchen.de/11843/1/1998_CEE_Telecommunications_Investment_and_ Economics_Growth.pdf

3. Czernich, N., Falck, O., Kretschmer, T., \& Woessmann, L. (2011). Broadband infrastructure and economic growth. The Economic Journal, 121(552), 505-532. Available from: http://citeseerx.ist.psu.edu/viewdoc/download?doi=10.1.1.456.4635\&rep=rep1\&type=pdf

4. Qiang, C. Z. W., Rossotto, C. M., \& Kimura, K. (2009). Economic impacts of broadband. Information and communications for development 2009: Extending reach and increasing impact, 3, 35-50. Available from: https://pdfs.semanticscholar.org/40e5/bf124f10056e4b02d7149bf1a0bd1a221b37.pdf

5. Ghosh, S. (2017). Broadband penetration and economic growth: Do policies matter?. Telematics and Informatics, 34(5), 676-693. Available from https://www.sciencedirect.com/science/article/abs/pii/S0736585316305135

6. Hasbi, M. (2017). Impact of Very High-Speed Broadband on Local Economic Growth: Empirical Evidence. Available from. https://www.econstor.eu/handle/10419/168484,

7. Nina Czernich, Oliver Falck, Tobias Kretschmer, Ludger Woessmann, Broadband Infrastructure and Economic Growth, The Economic Journal, Volume 121, Issue 552, May 2011, Pages 505-532, https://doi.org/10.1111/j.1468-0297.2011.02420.x Available from: https://academic.oup.com/ej/article-abstract/121/552/505/5079720

8. Biagi, F., \& Falk, M. (2017). The impact of ICT and e-commerce on employment in Europe. Journal of Policy Modeling, 39(1), 1-18. Available from:

https://fardapaper.ir/mohavaha/uploads/2018/07/Fardapaper-The-impact-of-ICT-and-ecommerce-on-employment-in-Europe.pdf

9. Minges, M. (2015). Exploring the relationship between broadband and economic growth. https://pdfs.semanticscholar.org/03a0/d34aaae2f7e6eb2d269c911e6b11b8fd01fd.pdf

10. Mitrović, Đ. (2015). BROADBAND ADOPTION, DIGITAL DIVIDE, AND THE GLOBAL ECONOMIC COMPETITIVENESS OF WESTERN BALKAN COUNTRIES. Ekonomski Anali/Economic Annals,60(207). Available from: http://www.doiserbia.nb.rs/img/doi/00133264/2015/0013-32641507095M.pdf 
11. Madalina-Vanesa Vargas, 2018. "Analysis of the e-Commerce Development in the Balkans," Academic Journal of Economic Studies, Faculty of Finance, Banking and Accountancy Bucharest,"Dimitrie Cantemir" Christian University Bucharest, vol. 4(3), pages 63-69, September, Available from: http://www.zbw.eu/econisarchiv/bitstream/handle/11159/2496/1037060997.pdf?sequence=1

12. UNICTAD (2015), Digital Economy Report 2015, Available from: https://unctad.org/en/PublicationsLibrary/ier2015_en.pdf

13. International Trade Centre, http://www.intracen.org/, http://www.intracen.org/itc/sectors/services/e-commerce/

14. ITU (2011) 'Handbook for the collection of administrative data on Telecommunications/ICT', p. 152. Available from: http://www.itu.int/dms_pub/itu-d/opb/ind/D-IND-ITC_IND_HBK2011-PDF-E.pdf.

15. Robert F. Engle; C. W. J. Granger (1987)., Co-Integration and Error Correction: Representation, Estimation, and Testing Econometrica, Vol. 55, No. 2. (Mar., 1987), pp. 251276., Available from: http://www.ntuzov.com/Nik_Site/Niks_files/Research/papers/stat_arb/EG_1987.pdf

16. Granger, Clive WJ.(1981) "Some properties of time series data and their use in econometric model specification." Journal of econometrics 16, no. 1 (1981): 121-130.

17. Granger, C. W., Newbold, P., \& Econom, J. (2001). Spurious regressions in econometrics. A Companion to Theoretical Econometrics, Blackwell, Oxford, 557-561. Available from: https://wolfweb.unr.edu/ zal/STAT758/Granger_Newbold_1974.pdf

18. Newbold, P., \& Granger, C. W. J. (1974). Spurious regressions in econometrics. Journal of Econometrics, 2(2), 111-120. Available from: https://wolfweb.unr.edu/ zal/STAT758/Granger_Newbold_1974.pdf

19. Granger, C. W., Newbold, P., \& Econom, J. (2001). Spurious regressions in econometrics. A Companion to Theoretical Econometrics, Blackwell, Oxford, 557-561. https://wolfweb.unr.edu/ zal/STAT758/Granger_Newbold_1974.pdf

20. Johansen, S. (1988). Statistical analysis of cointegration vectors. Journal of economic dynamics and control, 12(2-3), 231-254., Available from: https://pdfs.semanticscholar.org/012f/7d74a24ba58e0d965295e4a2eea4dc33531f.pdf

21. DICKEY, D. A., \& FULLER, W. A. (1979). With< 1 Unil Root. Journal of the American Statistical Association, 74(366), 427-431. Available from: http://u.arizona.edu/ rlo/readings/278799.pdf

22. Kwiatkowski, D., Phillips, P. C., Schmidt, P., \& Shin, Y. (1992). Testing the null hypothesis of stationarity against the alternative of a unit root: How sure are we that economic time series have a unit root?. Journal of econometrics, 54(1-3), 159-178., Available from: http://cba2.unomaha.edu/faculty/mwohar/WEB/links/Econometrics_papers/KPSS.pdf

23. Lütkepohl, H., \& Xu, F. (2012). The role of the log transformation in forecasting economic variables. Empirical Economics, 42(3), 619-638. Available from: https://www.econstor.eu/bitstream/10419/26636/1/595754392.PDF

24. Dimitrova, V., Kaneva, M. (2018) Electronic Commerce and Gross Domestic Product Growth in Bulgaria. 5th International Multidisciplinary Scientific Conference on Social Science \& Arts: SGEM 2018: Conference Proceedings, 24 Aug. - 2 Sept. 2018, Albena : STEF93 Technology Ltd., Vol.5. Modern Science, 2018, N 1.5, 297 - 304. 